\title{
Autochthonous yeasts as one of the tools to produce wines by original technologies
}

\author{
Eva Vontrobová ${ }^{1}$, Petra Kubizniaková ${ }^{1}$, Jaromír Fiala ${ }^{1}$, Jiří Sochor ${ }^{2}$, Dagmar Matoulkováa ${ }^{* 1}$ \\ ${ }^{1}$ Research Institute of Brewing and Malting, Lípová 15, 12044 Praha \\ ${ }^{2}$ Faculty of Horticulture, Mendel University in Brno, Valtická 337, 69144 Lednice \\ *Corresponding author:matoulkova@beerresearch.cz
}

\begin{abstract}
This review focuses on autochthonous wine yeasts that occur naturally in a specific geographical area, and their role in wine production. The distribution of individual species changes during ripening and processing of grapes and fermentation of the grape must. The composition of autochthonous microflora is influenced by many factors including interspecific interactions. Autochthonous yeast populations lend to wine flavor and taste typical for a specific geographical area. The article describes the fermentation of grape must, changes of autochthonous yeast microflora during spontaneous or combined fermentation, and includes an overview of the basic species of autochthonous yeasts.
\end{abstract}

Key words: autochtonous yeast, extracellular enzymes, Hanseniaspora uvarum, non-Saccharomyces, spontaneous fermentation, wine

\section{Introduction}

Autochthonous wine yeasts are naturally occurring in a specific geographical area and are typical for each vineyard. They produce many sensory-active compounds and thus influence the aromatic character of the wine. Yeast other than Saccharomyces, the so-called nonSaccharomyces, produce important extracellular enzymes that influence grape yield, wine purity, etc. (Manzanares et al., 2011). Due to different composition of yeast species on grapes / land with grapevine / vineyard, each wine fermented by autochthonous yeasts receives unique aroma and flavor. On the other hand, when only commercially produced active dried yeast is used in induced fermentation, it leads to a narrow aromatic profile and uniformity of wine (Furdíková and Malík, 2008).

The predominant species on the grapes is Hanseniaspora uvarum (formerly classified as Kloeckera apiculata). Strictly aerobic and / or weakly fermentative yeasts may also be found in lesser proportions. The grape microflora can be affected by a wide variety of factors such as temperature, rainfall, altitude, use of fungicides or ripeness of the grape. The vector is especially air (wind) and insects. The microflora associated with winery equipment is largely composed of Saccharomyces cerevisiae that is responsible for alcoholic fermentation (Aranda et al., 2011).

\section{Wine yeast}

Yeast taxonomy often uses two names for a single genetic species depending on the life cycle of the cell - the teleomorph (sexual stage) and the anamorph (vegetative stage). In the vegetative form, yeasts reproduce by budding or fission, during sexual reproduction they create spores. Wine yeasts with both stages include (teleomorph / anamorph): Dekkera / Brettanomyces, Metschnikowia pulcherrima / Candida pulcherrima, Hanseniaspora uvarum / Kloeckera apiculate and Torulaspora delbrueckii / Candida colliculosa. Winemakers use an informal name of yeast based on their morphology, function and other characteristics. Hanseniaspora uvarum (Kloeckera apiculate) is often referred to as an apiculate yeast due to its lemon-shaped morphology. Hanseniaspora together with Candida, Cryptococcus, Debaryomyces, Hansenula, Issatchenkia, Kluyveromyces, Metschnikowia, Pichia and Rhodotorula are also called "native / wild" yeasts because they originate in the wine environment. However, other yeasts also are present naturally in the wine environment (e.g. Saccharomyces), and so the term "native / wild" ceased to be used (Fugelsang and Edwards, 2006). The term "non-Saccharomyces yeasts" is now more commonly used to describe yeasts that are not of the genus Saccharomyces. Members of the genus Saccharomyces involved in the primary fermentation are sometimes called "fermentative yeasts". Candida, Hansenula or Pichia can grow in unfilled containers in the presence of oxygen, growing on the surface of the young wine in the form of flor (pellicle). These yeasts are referred to as pellicle-forming yeasts or also "film yeasts" (Fugelsang and Edwards, 2006; Minárik, 2009).

Traits of the wine yeast $S$. cerevisiae relate to the variety of grapes and geographical origin (Tab. 1). Wild strains of yeast produce wine with earthy and sulphurous aroma, whereas domesticated strains produce predominantly fruity and floral aroma (Hyma et al., 2011). The final taste and quality of wine are affected by both the variety of grapes, the technological process and genotype of yeast, as well as by stress factors, for example changes in the concentration of oxygen, osmotic pressure, $\mathrm{pH}$, ethanol concentration, temperature stress, availibility of nutrients, etc. (Belda et al., 2017; Vontrobová et al., 2017).

Traditional wine-production uses autochthonous yeasts that are on the surface of grapes and in the wine 
Table 1: Specific traits of S. cerevisiae strains from different locations (Tofalo et al., 2013; modified)

\begin{tabular}{|l|l|}
\hline Geographical origin & Specific traits \\
\hline West Africa & Poor utilization of galactose \\
\hline & Hypersensitivity to high temperatures \\
\hline European & High respiratory capability (ethanol growth) \\
\hline & Good proliferation in wine must \\
\hline & $\begin{array}{l}\text { Good tolerance to copper, tartaric acid, } \mathrm{Na}^{+} \text {and } \\
\mathrm{Li}^{+}\end{array}$ \\
\hline Malaysia & Utilization of melibiose and mannitol \\
\hline North America & Unable to metabolize maltose \\
\hline & Tolerance to oxalic acid \\
\hline
\end{tabular}

environment. Yeasts appear on grapes at the beginning of the ripening and are transmitted to grapes by insects or air. The amount of yeast on berries of Vitis vinifera ranges from $10^{4}$ to $10^{6} / \mathrm{cm}^{2}$ of the surface of berries. The highest number of yeasts on grapes occur in a warm climate (Fleet et al., 2002).

The predominant species on the surface of the grapes is Hanseniospora uvarum (Kloeckera apiculate) that account for more than $50 \%$ of the total yeast population. Strictly aerobic (e.g. Rhodotorula) and slightly fermentative yeasts with low tolerance to alcohol are found in low levels on grapes. Included are, for example: Candida (C. famata, C. stellata), Cryptococcus, Debaryomyces, Hansenula (H. anomala), Issatchenkia, Kluyveromyces, Metschnikowia (M. pulcherrima), Pichia ( $P$. fermentans, $P$. membranifaciens) and Rhodotorula (Aranda et al., 2011; Ribereau-Gayon et al., 2006). Fermentative yeasts $S$. cerevisiae and $S$. bayanus are found on grapes only to a limited extent. Especially $S$. cerevisiae is found on the technological equipment in the winery. Brettanomyces, Candida, Hansenula, Hanseniaspora, Pichia and Torulaspora have also been isolated from the winery (Aranda et al., 2011).

\section{Types of grape must fermentation}

There are three types of wine fermentation: induced, spontaneous and combined. Induced fermentation uses active dry wine yeast $S$. cerevisiae, that ensures a seamless fermentation with minimal formation of by-products of anaerobic glycolysis. By-products can create unwanted side-effects of wine tones. When dry yeasts are used, yeasts that are not a natural part of the vineyards get in the must and the authenticity of the wines is thus disturbed. Induced fermentation is used by most winemakers. Recently, more and more wineries are turning to spontaneous fermentation (Furdíková and Malík, 2008).

Starter cultures are able to initiate fermentation in a short time while limiting the potential for spoilage. The starter culture of Saccharomyces can inhibit the population of non-Saccharomyces (Fugelsang and Edwards, 2006). There are some exceptions, when non-Saccharomyces (e.g. Hanseniaspora uvarum and Candida) develop in the presence of a Saccharomyces starter culture (Heard and Fleet, 1985). During must fermentation by mixed non-Saccharomyces and Saccharomyces cultures the starter Saccharomyces culture is affected in the level of expression of genes that are involved in, e.g., higher alcohol production (Barbosa et al., 2015). Thus the sensoric quality of wine has improved when Chenin Blanc must was inoculated by a combined culture of $C$. pulcherrima and $S$. cerevisiae (Jolly et al., 2003). The growth of non-Saccharomyces yeasts can be improved by reducing fermentation temperature $\left(10-15{ }^{\circ} \mathrm{C}\right)$ (Fugelsang and Edwards, 2006). Spontaneous / natural fermentation uses only autochthonous microorganisms. When autochthonous yeasts and bacteria are used, a typical aromatic profile is preserved. During spontaneous fermentation, different species and strains of yeast and bacteria are being promoted with different intensity. The control of the fermentation process is more difficult. Depletion of growth factors and unpredictable enzymatic effects can occur (Furdíková and Malík, 2008). Spontaneous and induced fermentation can be combined. The combined fermentation uses autochthonous yeasts isolated from the vineyard as starter culture. In the Czech Republic Znovín Znojmo, a.s., Sonberk, a.s. or Popice produce wine with autochthonous yeasts (Furdíková and Malík, 2008).

Although induced fermentation is predominant in wine industry, spontaneous fermentation is becoming more and more used by winemakers. Autochthonous yeasts produce many sensory-active compounds and extracellular enzymes that affect the final quality of wine. Wine produced by spontaneous fermentation has a characteristic aroma and flavour which distinguish it from the wine on the market (Fig. 1).

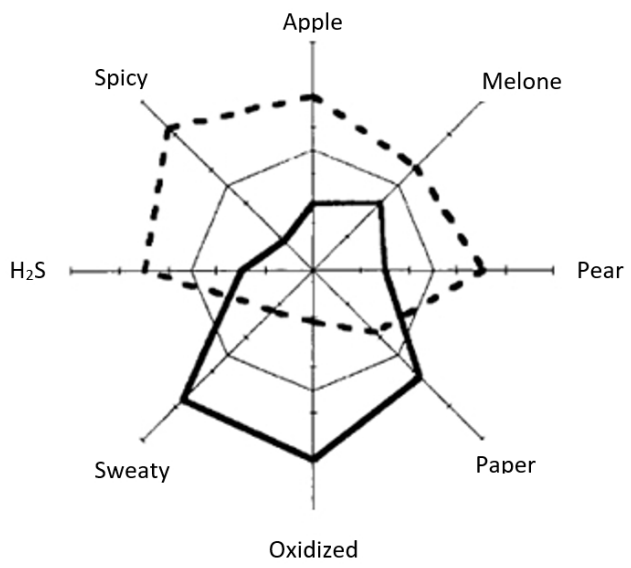

Figure 1: The effect of spontaneous (dashed line) and induced (thick line) fermentation on the sensory characteristics of Riesling wine (thin line) (Jackson 2008; modified). 
Non-Saccharomyces yeasts, inter alia, differ from saccharomycetes by producing extracellular enzymes that significantly affect some phases of the production process (grape maceration, filtration, clarification) and at the same time increase grape yield and extraction of colors (Charoenchai et al., 1997). The grapes contain various structural substances (pectins, cellulose, glycans, lignin, etc.), aromatic precursors, phenols and enzymes. Under normal vinification conditions, the grapes produce only small quantities of enzymes with very limited activity which is not sufficient for effective degradation of structural substances that are contained in the grapes. The controlled use of non-Saccharomyces yeasts increases yield and color extractions and positively improves particular phases of the process (must clarification or wine filtration) (Aranda et al., 2011). Non-Saccharomyces yeasts produce esterases, glycosidases, lipases, $\beta$-glucosidases, proteases, cellulases, etc. The production of individual enzymes is described below within the taxon characteristics.|

\section{Changes in yeast populations during fermentation}

The composition of yeasts is changing during spontaneous fermentation of grape must (Fig. 2). During the first few hours after filling the fermentation vessel, yeasts occurring in the must are identical to the grape microflora. Most common non-Saccharomyces yeasts (A) are Hanseniaspora uvarum (predominant) and Candida stellate (Jackson, 2008). Saccharomyces that control alcoholic fermentation appear in higher numbers after 20 hours and are predominant after $3-4$ days. After the primary fermentation is finished, malolactic fermentation (C) may be induced by lactic acid bacteria (e.g. Oenococcus). Spoilage yeasts and bacteria are also present during the production of wine and their concentration is highest during the aging of wine (D).

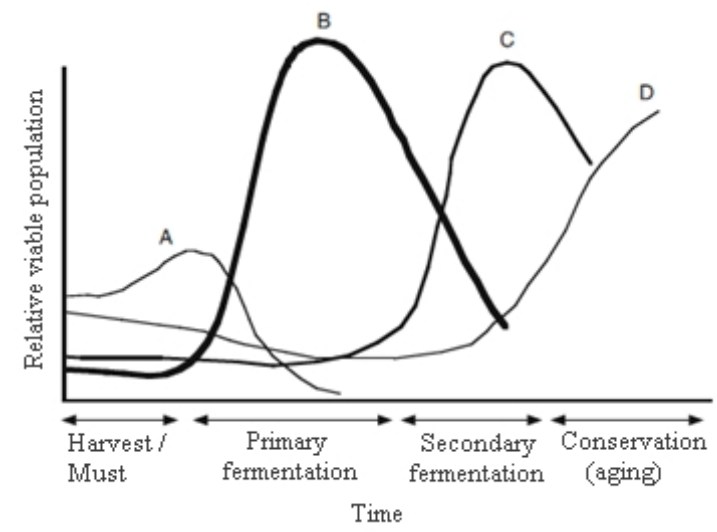

Figure 2: The composition of yeasts during fermentation of grape must; A, non-Saccharomyces yeasts; B, Saccharomyces yeasts; $C$, Oenococcus oeni; $D$, spoilage yeast and/or bacteria (Fugelsang and Edwards, 2006; modified).

This change in the yeast population is linked to the increasing concentration of ethanol, the anaerobic conditions, the use of sulphites (Fig. 3), higher temperature and the change of sugar content (Aranda et al., 2011). Low temperatures of fermentation $\left(10-15{ }^{\circ} \mathrm{C}\right)$ can cause increased tolerance of non-Saccharomyces yeasts to ethanol (Gao and Fleet, 1988).

The initial concentration of yeast ranges from $10^{3}$ to $10^{6}$ cells / ml. Non-Saccharomyces yeasts (predominantly Hanseniaspora uvarum) dominate. Most strains present at the start of fermentation soon pass into decline. This is often caused by the increasing concentration of ethanol produced by Saccharomyces yeasts or the addition of sulfur dioxide (Jackson, 2008).

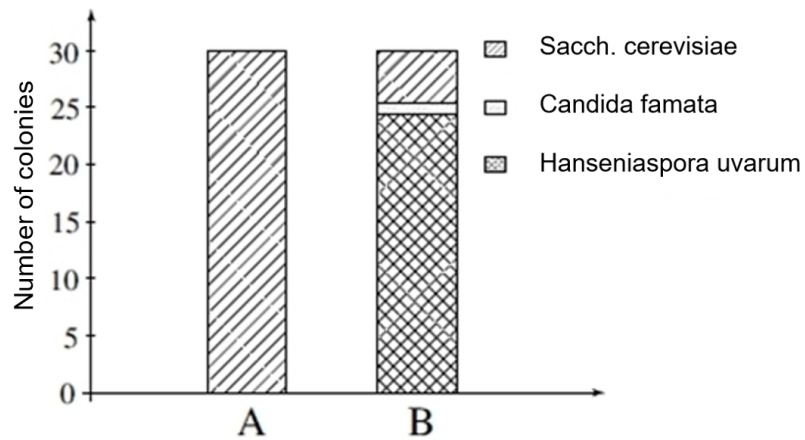

Figure 3: Comparison of yeast species present at the start of alcoholic fermentation. Yeast in a tank of sulfited red grapes in Bordeaux (A). Yeast in a tank of unsulfited white must in Cognac (B) (Ribereau-Gayon et al., 2006; modified).

Recent studies indicate that interspecies / interstrain effects may play a role such as the production of acetaldehyde by hybrid strain of $S$. cerevisiae and $S$. uvarum (Cherait et al., 2005) or a cell-cell contact (Jackson, 2008). The content of acetaldehyde in wine may range from 30 to $300 \mathrm{mg} / \mathrm{l}$. The concentration of acetaldehyde in white wine is usually higher $(80 \mathrm{mg} / \mathrm{l})$ than that in red wine $(30 \mathrm{mg} / \mathrm{I})$. The presence of acetaldehyde can be masked by the addition of $\mathrm{SO}_{2}$ (Vontrobová et al., 2017).

During the initial stages of fermentation, nonSaccharomyces yeasts produce different chemical compounds such as acetic acid, glycerol and esters. This can modify the final wine's aroma. Some strains of Hanseniaspora uvarum produce up to 25 times the amounts of acetic acid typically produced by $H$. uvarum. These yeasts may inhibit some $S$. cerevisiae strains, possibly due to the production of acetic, caprylic and capric acids (Jackson, 2008). In favorable conditions, characterized by a complete exhaustion of sugars at the end of fermentation, the number of yeasts decreases. What remains is almost exclusively $S$. cerevisiae. The viable populations of $S$. cereviase also drop rapidly, falling below a few hundred cells $/ \mathrm{ml}$. In some cases, spoilage yeasts (e.g. Brettanomyces intermedius) can contaminate the aging wine. Some yeasts such as Pichia, Candida, Hansenula and certain strains of $S$. cerevisiae form a veil on the surface of the wine. Strains of $S$. cerevisiae that form a veil are used in the production of specialty wines. Refermentation yeasts can develop significantly in sweet or botrytized sweet wine during aging or storage, the major species found are Saccharomycodes ludwigii, Zygosaccharomyces bailii and also some $S$. cerevisiae strains that are particularly resistant to ethanol and sulfur dioxide (Ribereau-Gayon et al., 2006). 


\section{Representatives of autochthonous yeasts}

\section{Candida}

The genus Candida represents a very broad group of species found in wines. The teleomorphic forms are represented by a number of yeasts: Issatchenkia, Kluyveromyces, Pichia, Metschnikowia, Saccharomyces, Torulaspora and Zygosaccharomyces. Various sugars may be fermented, and nitrate may be assimilated depending on the species. C. stellata assimilates and ferments glucose, sucrose, and raffinose. Other species (e.g. C. pulcherrima) ferment only glucose but assimilate glucose, galactose, sucrose, cellobiose, ethanol, glycerol, succinate and other compounds (Fugelsang and Edwards, 2006). Candida vini form a veil on the surface of wine and synthesize sensorially active compounds such as ethyl acetate or acetoin (Clemente-Jimenez et al., 2004). Some Candida species produce extracellular enzymes pectinases, enzymes cleaving heteropolysaccharides, structural compounds of grapes and proteolytic enzymes that are involved in the removal of protein turbidity of wine (Aranda et al., 2011; Lagace and Bisson, 2000).

\section{Dekkera/Brettanomyces}

Dekkera (teleomorph) / Brettanomyces (anamorph) is considered to be a cause of wine spoilage due to the production of volatile phenols (4-vinylphenol, 4vinylguaiacol, 4-ethylphenol and 4-ethylguaiacol) and nitrogenous compounds (2-acetyl-3,4,5,6-tetrahydropyridine, 2-acetyl-1,2,5,6-tetrahydropyridine and 2-ethyl-3,4,5,6tetrahydropyridine). In the case of special wines, the contamination by Dekkera may be desirable (Schifferdecker et al., 2014). All species ferment glucose, and other carbohydrates may be fermented depending on strain. Wine strains of Brettanomyces can be separated on the basis of lactose fermentation and succinate assimilation. The species $B$. anomalus (ferments lactose, assimilates succinate) and $B$. bruxellensis (does not ferment lactose, does not assimilate succinate) can be distinguished. Both yeasts can assimilate nitrate. Some members use ethanol as an only carbon and energy source (Silva et al., 2004). Species of Dekkera produce a large amount of acetic acid when grown on glucose (Freer, 2002).

Brettanomyces are not primarily found on grapes. They are transmitted by infected wine, equipment or fruit flies (Fugelsang and Edwards, 2006). Brettanomyces were found in air samples (Connell et al., 2002) and are generally observed in barrel-aging red wine, although they have also been noted in sparkling wines or white wine (Chardonnay and Sauvignon Blanc) (Ciani and Ferraro, 1997). The presence of the yeast is related to the disaccharide cellobiose which results from the toasting process of wooden barrels (Blondin et al., 1982). Brettanomyces yeasts grow very slowly. Their growth reaches a maximum population density 5 to 7 months after vinification (Fugelsang and Zoecklein, 2003). The low content $(0.275 \mathrm{~g} / \mathrm{l})$ of residual sugar supports the growth of Bretannomyces; they are therefore more often isolated from dry wine (Chatonnet et al., 1995).

\section{Hanseniaspora}

Hanseniaspora forms ovoid/spherical (young cultures) or apiculate (older cultures) cells (Fugelsang and Edwards, 2006). The species is most commonly found in grapes.
H. uvarum (anamorph Kloeckera apiculata) ferments only glucose and assimilates glucose, cellobiose, 2-keto-Dgluconate and salicin. Hanseniaspora is often fructophilic and prefers fructose over glucose (Ciani and Fatichenti, 1999). Some Hanseniaspora species are the highest producers of proteolytic activity and affect the protein profile (and thus turbidity) of the finished wines (Dizy and Bisson, 2000; Lagace and Bisson, 2000). Hanseniaspora yeasts can produce significant quantities of some wine compounds; $H$. guilliermondii produces 2-phenylethyl acetate and $H$. uvarum produces isoamyl acetate (Moreira et al., 2008).

\section{Issatchenkia}

Issatchenkia terricola and I. orientalis (anamorph Candida krusei) are found in wine. I. orientalis forms ovoid cells, assimilates glucose, $\mathrm{N}$-acetyl-D-glucosamine, ethanol, glycerol, D-lactate and succinate (Fugelsang and Edwards, 2006). I. terricola appears as ovoidal to elongated cells, assimilates glucose, ethanol, glycerol and succinate (Kurtzman et al., 2011). Malic acid and tartaric acid are the major organic acids in the grapes. Issatchenkia orientalis degrades malic acid, which can have a negative impact on wine quality. Among the yeasts degrading malic acid are Schizosaccharomyces pombe, Schizosaccharomyces malidevorans and Zygosaccharomyces bailii (Kim et al., 2008). Issatchenkia terricola shows $\beta$-glucosidase activity. $\beta$-Glucosidases can promote the liberation of aromatic compounds from monoterpene glycoside precursors present in young wine (González-Pombo et al., 2011).

\section{Metschnikowia}

Metschnikowia is found in the grapes, musts or wines. M. pulcherrima (anamorph Candida pulcherrima) ferments glucose and assimilates a number of compounds (e.g. galactose, maltose, cellobiose, ethanol, glycerol, D-manitol) but not nitrate (Fugelsang and Edwards, 2006). As nitrogen sources it assimilates cadaverine, L-lysine and ethylamine. The yeast tolerates $10 \mathrm{mg} / \mathrm{l}$ cycloheximide but is completely inhibited by it at $100 \mathrm{mg} / \mathrm{l}$. Some species produce pulcherrimin - a brown/red pigment (Pallmann et al., 2001). M. pullcherrrima has antimicrobial activity against the non-Saccharomyces yeasts Brettanomyces / Dekkera, Hanseniaspora and Pichia, but does not have any influence on the growth of $S$. cerevisiae and can co-ferment with it. The antimicrobial activity is not based on protein compounds but is related to the production of pulcherriminic acid (precursor of pulcherrimin pigment) which immobilizes the iron in the growth medium (Oro et al., 2014). Growth of $S$. cerevisiae is not inhibited by M. pulcherrima and these species can thus co-ferment, resulting in elevated production of ethyloctanoate (pear aroma) by $M$. pulcherrima (Sadoudi et al., 2012). Some strains of $M$. pulcherrima are able to produce higher concentration of 3-mercaptohexanol that is important for white wine aroma (Belda et al., 2017). M. pulcherrima produces aspartic protease which can increase the concentration of assimilable nitrogen sources, impact aromatic profile and reduce wine protein haze (Reid et al., 2012).

\section{Meyerozyma}

The species Meyerozyma guilliermondii, which was previously classified as Pichia guilliermondii, occurs in must and on 
winery equipment (Dias et al., 2003; Kurtzman et al., 2011). Asexual vegetative stage (anamorph) is referred to as Candida guilliermondii (Romi et al., 2014). Meyerozyma forms ovoid/elongated cells, ferments sugars and assimilates hexoses, disaccharides, polyols and organic acids (Kurtzman et al., 2011).

\section{Pichia}

The genus Pichia has previously included more than 100 types of yeast; most of them were reclassified into other genera; at present the genus Pichia includes about 20 species. The only fermented sugar is glucose (Kurtzman et al., 2011). Three species are linked to viticulture: "P. anomala" (now Wickerhamomyces anomalus), P. membranifaciens and "P. guilliermondii" (now Meyerozyma guilliermondii) which are found in grape must, wine or on winery equipment (Dias et al., 2003).

P. membranifaciens is found in wine, slightly ferments glucose and assimilates only a limited number of compounds (glucose, N-acetyl-d-glucosamine, ethanol). Some species of the Pichia genus ( $P$. anomala, $P$. kluyveri, $P$. membranifaciens, Pichia guilliermondii - now Meyerozyma guilliermondii) produce pectinases which positively affect the wine aroma (Aranda et al., 2011). Elevated production of 3-mercaptohexanol was observed during co-fermentation of P. kluyveri with S. cerevisiae (Anfang et al., 2009).

Yeasts of the genus Pichia utilize acids and thus increase $\mathrm{pH}$ (Fugelsang and Edwards, 2006). They produce proteins to prevent the growth of spoilage microorganisms (Blaszczyk et al., 2015)

\section{Saccharomyces}

Saccharomyces yeasts feature ovoid- or ellipsoid-shaped cells. S. cerevisiae and $S$. bayanus are mainly found in wine. They ferment glucose, sucrose, raffinose and ethanol and do not utilize five-carbon sugars (pentoses). Over the years, there have been numerous changes to the taxonomy of the genus Saccharomyces (Fugelsang and Edwards, 2006).

Formerly, Saccharomyces yeasts were divided into three groups: sensu stricto, sensu lato and $S$. kluyveri. The sensu stricto complex included S. cerevisiae, S. pastorianus, $S$. bayanus, which are typical for fermentation industry (Fernández-Espinar et al., 2003), and S. kudriavzevii, S. cariocanus and S. mikatae (Naumov et al., 2000). The sensu lato complex included S. exiguus, S. castellii, S. unisporus, S. dairenesis and S. servazzii (Petersen et al., 1999). S. kluyveri is now officially described as Lachancea kluyveri (Agier et al., 2013). Yeasts from the sensu lato complex were reclassified to form a separate group: Kazachstania, Naumovozyma and Lachancea (Kurtzman et al., 2011). Based on PCR analysis, $S$. cariocanus is considered an American variant of $S$. paradoxus (Muir et al., 2011). At present, 9 valid species belong to the Saccharomyces genus: S. cerevisiae, S. arboricolus, S. paradoxus, S. mikatae, S. kudriavzevii, S. eubayanus, $S$. uvarum and two species with hybrid genome S. bayanus and S. pastorianus (Fig. 4).

Interspecific crossings can arise between $S$. cerevisiae and closely related species or genera. In hybridization of closely related yeast, hybrid yeasts feature higher viability (Marinoni et al., 1999). The hybridization affects vitality and phenotypic values of the offspring. Characteristics of the hybrid genome affect the taste and aroma of alcoholic beverages. Numerous interspecific hybrids between $S$. cerevisiae, $S$. uvarum and $S$. kudriavzevii have been isolated in the environment (da Silva et al., 2015). The increasing competition in the wine sector gives rise to yeast breeding which affects the production of metabolites and thus taste and aroma of the beverages.

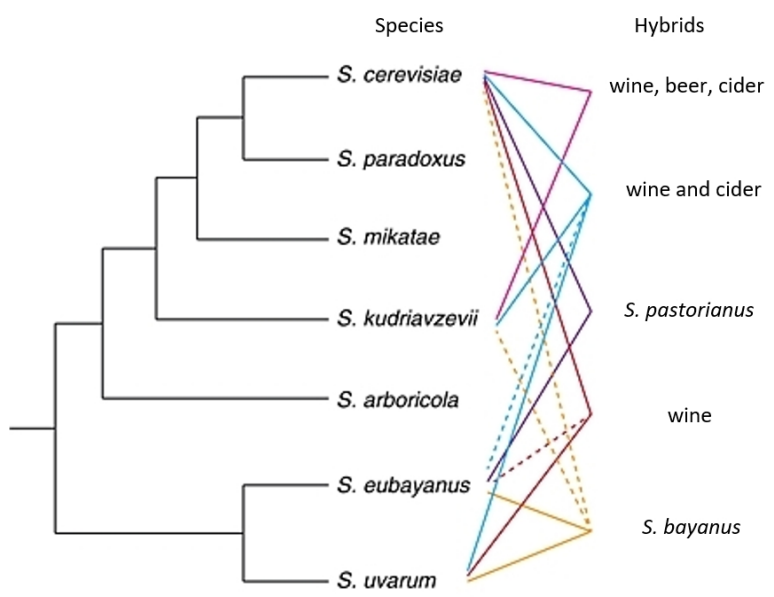

Figure 4. Phylogenetic relationships among Saccharomyces species. Dashed lines represent introgressions from a third or fourth species into a hybrid (Boynton and Greig 2014; modified).

Based on restriction analysis and sequencing of the mitochondrial COX2 gene, hybrids were identified in wine industry (González et al., 2006); in particular, hybrids of S. cerevisiae/S. kudriavzevii, S. cerevisiae/S. kudriavzevii/ S. uvarum and S. cerevisiae/S. uvarum (Sipiczki, 2008).

The S. cerevisiae/S. kudriavzevii hybrid has been found to be mainly associated with winemaking and is best suited for winemaking under the typical fermentation conditions of central Europe, low temperatures and low sugar content in grapes of Vitis vinifera (González et al., 2006). A VIN7 allotriploid hybrid genome is the result of crossing $S$. cerevisiae with $S$. kudriavzevii. The VIN7 hybrid has the ability to grow at low temperature and the ability to release double amounts of the fruity thiol 4-mercapto-4-methylpentan-2-one (4MMP) which affects the wine aroma (Borneman et al., 2012).

\section{Saccharomycodes}

This genus is represented by a single species, Saccharomycodes ludwigii. Fermented sugars include glucose, sucrose and raffinose; assimilated compounds are glucose, sucrose, raffinose, glycerol, cadaverin and ethylamine but not nitrate (Fugelsang and Edwards, 2006). Saccharomycodes ludwigii is highly resistant to ethanol (12-14\%) and $\mathrm{SO}_{2}$ (up to $200 \mathrm{mg} / \mathrm{I}$ ) (Ivit et al., 2017). The resistance of this yeast could be due to its ability to produce acetaldehyde, which binds $\mathrm{SO}_{2}$ (Ciani and Maccarelli, 1998). Formerly, this yeast was considered spoilage yeast. The studies have lately been focusing on its positive impact. The cells produce a $\beta$-glucosidase enzyme involved in the release of aromatic compounds from non-aromatic precursors in the grapes and Saccharomycodes might thus positively affect the sensory profile of wine (Ivit et al., 2017). 


\section{Schizosaccharomyces}

The genus Schizosaccharomyces was initially considered as a spoilage yeast because of the production of undesirable metabolites (acetic acid, hydrogen sulfide, acetaldehyde). Currently, Schizosaccharomyces species have a great potential to produce less acidic wines with a lower histamine content, a higher anthocyanin content and a higher color intensity. Schizosaccharomyces reduces the concentration of malic acid, leading to malolactic fermentation in must which leads to a reduction of undesirable amines.

$S$. pombe can be an invaluable tool for wines with a high concentration of malic acid, especially for winemakers in northern wine regions (cold climates). S. pombe reduces the content of gluconic acid, reduces 4-ethylphenol (Mylona et al., 2016) and has urease activity, i.e. it lowers the content of urea (precursor of toxic ethyl carbamate) during the fermentation process (Benito et al., 2013).

\section{Wickerhamomyces}

W. anomalus (formerly P. anomala) has a limited fermentation ability (it ferments glucose and sucrose) and can grow in oxygen as a film on the surface of wine. If $W$. anomalus grows fermentatively, it produces 0.2 to $4.5 \%$ ethanol together with a large amount of acetic acid, ethyl acetate and isoamyl acetate (Shimazu and Watanabe, 1981). The CBS 1982 protein produced by $W$. anomalus is characterized by the highest antifungal activity against Candida pulcherrima and Hanseniaspora guilliermondii (Blaszczyk et al., 2015).

\section{Zygosaccharomyces}

Species isolated from wine mainly include $Z$. bailii, Z. bisporus, Z. rouxii and Z. florentinus. Saccharomyces rouxii and $Z$. barkeri are synonyms for $Z$. rouxii. Various sugars are fermented depending on species, nitrates are not assimilated. $Z$. rouxii ferments glucose and maltose, assimilates glucose, trehalose, glycerol, D-mannitol and D-glucitol.
Zygosaccharomyces produces succinic acid, acetic acid and lactic acid, acetaldehyde and glycerol. It has tolerance to preservatives, a high content of sugar and ethanol and low temperature $\left(2,5^{\circ} \mathrm{C}\right.$ ) (Fugelsang and Edwards, 2006; Thomas and Davenport, 1985). Zygosaccharomyces depreciates wine; the spoilage effects include gas production, sediments and film formation in bottled wines (Loureiro and Malfeito-Ferreira, 2003).

\section{Conclusion}

The spontaneous fermentation of grape must is based on autochthonous yeasts which are present naturally in the vineyard. The composition of the yeast population changes during grape processing and fermentation of grape must. The microflora composition is influenced by a number of factors: concentration of sugar and ethanol, oxygen availability, sulfur compounds or temperature. Interspecies interactions also play an important role. The predominant species on the grapes is Hanseniaspora uvarum (formerly classified as Kloeckera apiculata). The primary fermentation is predominantly controlled by Saccharomyces. Autochthonous yeast populations give a typical flavor and taste to wine depending on the geographical area. On the market, the wine produced in this way has the advantage of uniqueness. The disadvantage of spontaneous fermentation is a difficult control of the fermentation process, depletion of growth factors or unpredictable enzymatic effects. Spoilage yeasts (e.g. Dekkera) can contaminate the aging wine and disturb the quality of wine.

\section{Acknowledgement}

The article was elaborated with the support of the Ministry of Culture of the Czech Republic - project DG16P02R017 "Viticulture and enology for maintaining and restoring cultural identity wine regions in Moravia". 


\section{References}

Agier, N., Romano, O.M., Touzain, F., Cosentino Lagomarsino, M., Fischer, G., 2013: The spatiotemporal program of replication in the genome of Lachancea kluyveri. Genome Biol. Evol., 5: 370-388. DOI: 10.1093/gbe/evt014

Anfang, N., Brajkovich, M., Goddard, M.R., 2009: Cofermentation with Pichia kluyveri increases varietal thiol concentrations in sauvignon blanc. Aust. J. Grape Wine Res., 15: $1-8$.

Aranda, A., Matallana, E., Olmo, M.: Saccharomyces Yeasts I: Primary fermentation. In: Molecular wine microbiology. Carrascosa, A.V., Munoz, R., Garcia, G. (Eds.), Elsevier Inc., 2011, pp. 1-32. ISBN: 978-0-12-375021-1, DOI: 10.1016/B9780-12-375021-1.10001-3

Barbosa, C., Mendes-Faia, A., Lage, P., Mira, N.P., MendesFerreira, A., 2015: Genomic expression program of Saccharomyces cerevisiae along a mixed-culture wine fermentation with Hanseniaspora guilliermondii. Microb. Cell. Fact., 14: 1.

Benito, S., Palomero, F., Morata, A., Calderón, F., Palmero, D. Suárez-Lepe, J. A., 2013: Physiological features of Schizosaccharomyces pombe of interest in making of white wines. Eur. Food Res. Technol., 236(1): 29-36. DOI: 10.1007/s00217-012-1836-2 Belda, I., Ruiz, J., Esteban-Fernández, A., Navascués, E., Marquina, D., Santos, A., Moreno-Arribas, M.V., 2017: Microbial contribution to wine aroma and its intended use for wine quality improvement. Molecules, 22: 189. doi: $10.3390 /$ molecules22020189

Błaszczyk, U., Satora, P., Sroka, P., 2015: The influence of Pichia killer toxins on the wine spoilage yeasts. Potravinarstvo Slovak J. Food Sci., 9(1): 284-287. DOI: 10.5219/481

Blondin, B., Ratomahenina, R., Arnaud, A., Galzy, P., 1982: A study of cellobiose fermentation by a Dekkera strain. Biotechnol. Bioeng., 24(9), 2031-2037. DOI: 10.1002/bit.260240910

Borneman, A.R., Desany, B.A., Riches, D., Affourtit, J.P., Forgan, A.H., Pretorius, I.S., Egholm, M., Chambers, P.J., 2012: The genome sequence of the wine yeast VIN7 reveals an allotriploid hybrid genome with Saccharomyces cerevisiae and Saccharomyces kudriavzevii origins. FEMS Yeast Res., 12: 88-96. DOI: 10.1111/j.1567-1364.2011.00773.x

Boynton, P.J., Greig, D., 2014: The ecology and evolution of non-domesticated Saccharomyces species. Yeast, 31(12): 449-462. DOI: 10.1002/yea.3040

Charoenchai, C., Fleet, G.H., Henschke, P.A., Todd, B.E.N., 1997: Screening of non-Saccharomyces wine yeasts for the presence of extracellular hydrolytic enzymes. Aust. J. Grape Wine Res., 3: 2-8. DOI: 10.1111/j.1755-0238.1997.tb00109.x Chatonnet, P., Dubourdieu, D., Boidron, J.N., 1995: The influence of Brettanomyces/Dekkera sp. yeasts and lactic acid bacteria on the ethylphenol content of red wines. Am. J. Enol. Vitic., 46: 463-468.

Cheraiti, N., Guezenec, S., Salmon, J.M., 2005: Redox Interactions between Saccharomyces cerevisiae and Saccharomyces uvarum in mixed culture under enological conditions. Appl. Env. Microbiol., 71(1): 255-260. DOI: 10.1128/AEM.71.1.255260.2005

Ciani, M.,Ferraro, L., 1997: Role of oxygen on acetic acid production by Brettanomyces/Dekkera in winemaking. J. Sci. Food Agric., 75: 489-495. DOI: 10.1002/(SICI)10970010(199712)75:4<489:AID-JSFA902>3.0.CO;2-9

Ciani, M., Fatichenti, F., 1999: Selective sugar consumption by apiculate yeasts. Lett. Appl. Microbiol., 28(3): 203-206. DOI:10.1046/j.1365-2672.1999.00505.x

Ciani, M., Maccarelli, F., 1998: Oenological properties of non-Saccharomyces yeasts associated with wine-making. World J. Microbiol. Biotechnol., 14(2): 199-203. DOI: 10.1023/A:1008825928354

Clemente-Jimenez, J.M., Mingorance-Cazorla, L., MartínezRodríguez, S., Heras-Vázquez, F.J.L., Rodríguez-Vico, F., 2004: Molecular characterization and oenological properties of wine yeasts isolated during spontaneous fermentation of six varieties of grape must. Food Microbiol., 21(2): 149-155. DOI: 10.1016/S0740-0020(03)00063-7

Connell, L., Stender, H., Edwards, C.G., 2002: Rapid detection and identification of Brettanomyces from winery air samples based on peptide nucleic acid analysis. Am. J. Enol. Vitic.,
53(4): 322-324.

da Silva, T., Albertin, W., Dillmann C., Bely, M., la Guerche, S., Giraud, C., Huet, S., Sicard, D., Masneuf-Pomarede, I., de Vienne, D., Marullo, P., 2015: Hybridization within Saccharomyces genus results in homoeostasis and phenotypic novelty in winemaking conditions. PLoS One, 10(5): e0123834. DOI: 10.1371/journal.pone.0123834

Dias, L., Dias, S., Sancho, T., Stender, H., Querol, A., Malfeito-Ferreira, M., Loureiro, V., 2003: Identification of yeasts isolated from wine-related environments and capable of producing 4-ethylphenol. Food Microbiol., 20(5): 567-574. DOI:10.1016/S0740-0020(02)00152-1

Dizy, M., Bisson, L.F., 2000: Proteolytic activity of yeasts strains during grape juice fermentations. Am. J. Enol. Vitic., 51: 155-167.

Fernández-Espinar, T.M., Barrio, E., Querol, A., 2003: Analysis of the genetic variability in the species of the Saccharomyces sensu stricto complex. Yeast, 20(14): 1213-1226. DOI: 10.1002/yea.1034

Fleet, G.H., Prakitchaiwattana, C., Beh, A.L., Heard, G.M. 2002: The yeast ecology of wine grapes. Biodiversity and Biotechnology of Wine Yeasts(Ciani M, ed), pp. 1-17. Research Singpost, Kerala.

Freer, S.N., 2002: Acetic acid production by Dekkera/Brettanomyces yeasts. World J. Microbiol. Biotechnol. 18(3): 271-275. DOI: 10.1023/A:1014927129259

Fugelsang, K.C., Edwards, C.G., 2006: Wine Microbiology: Practical Applications and Procedures. ISBN 978-0-387-333410 .

Fugelsang, K.C., Zoecklein, B.W., 2003: Population dynamics and effects of Brettanomyces bruxellensis strains on Pinot noir (Vitis vinifera L.) Wines. Am. J. Enol. Vitic., 54(4): 294-300. DOI: $10.1038 / 76469$

Furdíková, K., Malík, F., 2008: Autochtónne kvasinky a ich aplikácia do vinárskej praxe. Vinařský obzor, 5: 234-235.

Gao, C., Fleet, G.H., 1988: The effects of temperature and $\mathrm{pH}$ on the ethanol tolerance of the wine yeasts, Saccharomyces cerevisiae, Candida stellata and Kloeckera apiculata. J. Appl. Microbiol., 65(5): 405-409. DOI:10.1111/j.13652672.1988.tb01909.x

González, S.S., Barrio, E., Gafner, J., Querol, A., 2006 Natural hybrids from Saccharomyces cerevisiae, Saccharomyces bayanus and Saccharomyces kudriavzevii in wine fermentations. FEMS Yeast Res., 6: 1221-1234. DOI: 10.1111/j.15671364.2006.00126.x

González-Pombo, P., Fariña, L., Carrau, F., Batista-Viera, F., Brena, B. M., 2011: A novel extracellular $\beta$-glucosidase from Issatchenkia terricola: Isolation, immobilization and application for aroma enhancement of white Muscat wine. Proc. Biochem., 46(1): 385-389. DOI: 10.1016/j.procbio.2010.07.016

Heard, G.M., Fleet, G.H., 1985: Growth of natural yeast flora during the fermentation of inoculated wines. Appl. Env. Microbiol., 50(3): 727-728.

Hyma, K.E., Saerens S.M., Verstrepen K.J., Fay, J.C., 2011 Divergence in wine characteristics produced by wild and domesticated strains of Saccharomyces cerevisiae. FEMS Yeast Res., 11(7): 540-551. DOI: 10.1111/j.1567-1364.2011.00746.x Ivit, N.N., Loira, I., Morata, A., Benito, S., Palomero, F., Suárez-Lepe, J.A., 2017: Making natural sparkling wines with non-Saccharomyces yeasts. Europ. Food Res. Tech., 1-11. DOI: 10.1007/s00217-017-3015-y

Jackson, R.S., 2008: Wine science: principles and applications. 3rd ed. ISBN 9780123736468.

Jolly, N.P., Augustyn, O.P.H., Pretorius, I.S., 2003: The use of Candida pulcherrima in combination with Saccharomyces cerevisiae for the production of Chenin blanc wine. S. Afr. J. Enol. Vitic., 24(2): 63-69. DOI: 10.21548/24-2-2641.

Kim, D.H., Hong, Y.A., Park, H.D., 2008: Co-fermentation of grape must by Issatchenkia orientalis and Saccharomyces cerevisiae reduces the malic acid content in wine. Biotechnol. Lett., 30(9): 1633-1638. DOI: 10.1007/s10529-008-9726-1 Kurtzman, C.P., 1998b: $42-$ Pichia. The Yeasts (Fourth Edition), pp. 273-352. DOI:10.1016/B978-044481312-1/50046-0 
Kurtzman, C.P., Fell, J.W., Boekhout, T., 2011: The yeasts: a taxonomic study., pp. 297-298, 621, 705. ISBN: 978-0-44452149-1

Lagace, L.S., Bisson, L.F.,1990: Survey of yeast acid protease for effectiveness of wine haze reduction. Am. J. Enol. Vitic., 41: 147-155.

Loureiro, V., Malfeito-Ferreira, M., 2003: Spoilage yeasts in the wine industry. Int. J. Food Microbiol., 86: 23-50. DOI: 10.1016/S0168-1605(03)00246-0

Manzanares, P., Vallés, S., Viana, F.: Non-Saccharomyces yeasts in the winemaking proces. In: Molecular wine microbiology. Carrascosa, A.V., Munoz, R., Garcia, G. (Eds.), Elsevier Inc., 2011, pp. 1-32. ISBN: 978-0-12-375021-1, DOI: 10.1016/B978-0-12-375021-1.10001-3

Marinoni, G., Manuel, M., Petersen, R.F., Hvidtfeldt, J., Sulo, P., Piškur, J., 1999: Horizontal transfer of genetic material among Saccharomyces yeasts. J. Bacteriol., 181(20): 6488-6496. Minárik, E., 2009: Kožkotvorné kvasinky a ich vplyv na stabilitu vína. Vinařský obzor, 3: 111-112.

Moreira, N., Mendes, F., Guedes de Pinho, P., Hogg, T., Vasconcelos, I., 2008: Heavy sulphur compounds, higher alcohols and esters production profile of Hanseniaspora uvarum and Hanseniaspora guilliermondii grown as pure and mixed cultures in grape must. Int. J. Food Microbiol., 124(3): 231-238. DOI: 10.1016/j.ijfoodmicro.2008.03.025

Muir, A., Harrison, E., Wheals, A., 2011: A multiplex set of species-specific primers for rapid identification of members of the genus Saccharomyces. FEMS Yeast Res., 11(7): 552-563. DOI: $10.1111 /$ j.1567-1364.2011.00745.x

Mylona, A.E., Del Fresno, J.M., Palomero, F., Loira, I., Bañuelos, M.A., Morata, A., Calderón, F., Benito, S. Suárez-Lepe, J.A., 2016: Use of Schizosaccharomyces strains for wine fermentation-Effect on the wine composition and food safety. Int. J. Food Microbiol., 232: 63-72. DOI: 10.1016/j.ijfoodmicro.2016.05.023

Naumov, G.I., James, S.A., Naumova, E.S., Louis, E.J., Roberts, I.N., 2000: Three new species in the Saccharomyces sensu stricto complex: Saccharomyces cariocanus, Saccharomyces kudriavzevii and Saccharomyces mikatae. Int. J. Syst. Evol. Microbiol., 50:1931-1942. DOI: 10.1099/00207713-50-5-1931 Oro, L., Ciani, M., Comitini, F., 2014: Antimicrobial activity of Metschnikowia pulcherrima on wine yeasts. J. Appl. Microbiol., 116(5): 1209-1217. DOI: 10.1111/jam.12446

Pallmann, C.L., Brown, J.A., Olineka, T.L., Cocolin, L., Mills D.A., Bisson, L.F., 2001: Use of WL Medium to profile native flora fermentations. Am. J. Enol. Vitic., 52(3): 198-203. http://www.ajevonline.org/content/52/3/198.article-info
Petersen, R.F., Nilsson-Tillgren, T., Piškur, J., 1999: Karyotypes of Saccharomyces sensu lato species. Int. J. Syst. Evol. Microbiol., 49: 1925-1931. DOI: 10.1099/00207713-49-4-1925 Ribéreau-Gayon, P., Dubourdieu, D., Donéche, B., 2006: Handbook of enology. 2nd ed., ISBN: 0-470-01034-7.

Reid, V.J., Theron, L.W., Toit, M. du, Divol, B., 2012: Identification and partial characterization of extracellular aspartic protease genes from Metschnikowia pulcherrima IWBT Y1123 and Candida apicola IWBT Y1384. Appl. Environ. Microbiol. 78(19): 6838-6849. DOI: 10.1128/AEM.00505-12

Romi, W., Keisam, S., Ahmed, G., Jeyaram, K., 2014: Reliable differentiation of Meyerozyma guilliermondii from Meyerozyma caribbica by internal transcribed spacer restriction fingerprinting. BMC Microbiol., 14: 52. DOI: 10.1186/1471-2180-14-52

Sadoudi, M., Tourdot-Marechal, R., Rousseaux, S., Steyer, D., Gallardo-Chacon, J.J., Ballester, J., Vichi, S., Guerin-Schneider, R., Caixach, J., Alexandre, H., 2012: Yeast-yeast interactions revealed by aromatic profile analysis of Sauvignon Blanc wine fermented by single or co-culture of non-Saccharomyces and Saccharomyces yeasts. Food Microbiol., 32: 243-253.

Shimazu, Y., Watanabe, M., 1981: Effects of yeast strains and environmental conditions on formation of organic acids in must during fermentation. J. Ferment. Technol., 59: 27-32.

Schifferdecker, A.J., Dashko, S., Ishchuk, O.P., Piškur, J., 2014: The wine and beer yeast Dekkera bruxellensis. Yeast, 31(9): 323-332. DOI: 10.1002/yea.3023

Silva, P., Cardoso, H., Gerós, H., 2004: Studies on the wine spoilage capacity of Brettanomyces/Dekkera spp. Am. J. Enol. Vitic., 55(1): 65-72.

Sipiczki, M., 2008: Interspecies hybridization and recombination in Saccharomyces wine yeasts. FEMS Yeast Res., 8(7): 9961007. DOI: $10.1111 /$ j.1567-1364.2008.00369.x

Thomas, D.S., Davenport, R.R., 1985: Zygosaccharomyces bailii - a profile of characteristics and spoilage activities. Food Microbiol., 2(2): 157-169. DOI: 10.1016/S0740-0020(85)80008-3 Tofalo, R., Perpetuini, G., Schirone, M., Fasoli, G., Aguzzi, I., Corsetti, A., Suzzi, G., 2013: Biogeographical characterization of Saccharomyces cerevisiae wine yeast by molecular methods. Frontiers in Microbiol., 4: 166. DOI: 10.3389/fmicb.2013.00166 Vontrobová, E., Kopecká, J., Rotková, G., Matoulková, D., 2017: Factors influencing the production of sensory active substances in brewer's and wine yeast. Kvasny Prum. 63(4): 173-189. DOI: $10.18832 / \mathrm{kp} 201720$ 